\title{
RECENSIÓN
}

\section{CASE STUDIES IN PUBLIC HEALTH ETHICS}

Coughlin SS, Soskolne CL, Goodman KW

American Public Health Association

Washington, DC

1997, ISBN 0-87553-232-2

180 páginas

Recensión: María José Tormo Díaz. Servicio de Epidemiología. Consejería de Sanidad y Política Social de la Regiôn de Murcia

La discusión abierta sobre las implicaciones éticas de algunas de las decisiones que se toman en relación con la salud de la población, es una tendencia en expansión con múltiples agentes implicados: autoridades sanitarias, investigadores, representantes de los ciudadanos, sociedades científicas, medios de comunicación, etcétera. Por otra parte, se acepta que las recomendaciones utilizadas en el campo de la asistencia clínica (en la que predominan los principios éticos de autonomía y de no-maleficencia) no son a menudo adecuadas en el campo de la salud pública (donde predominan los principios de justicia y beneficencia). Si durante la última década se habían elaborado recomendaciones sobre los aspectos éticos de la investigación epidemiológica — por ejemplo, las promovidas por el American College of Epidemiology (1985), las de la International Society for Environmental Epidemiology (1989), el Consejo Internacional de Organizaciones Médicas (1991), la Asociación Internacional de Epidemiología (1991) o, más recientemente, las de la Sociedad Española de Epidemiología (1998) - era urgente disponer, además, de material práctico que ayudara en los programas de formación de jóvenes salubristas y en la puesta al día de los profesionales ya experimentados. Este libro, editado por la Asociación Americana de Salud Pública, llena así un importante vacío, ya que está dedicado a la presentación y discusión de casos (sesenta) sobre la práctica y la investigación epidemiológica, así como a los conflictos que podríamos englobar bajo el amplio epígrafe de integridad en el proceso investigador, frecuentes en cualquier rama de la ciencia pero aquí presentados en situaciones fácilmente reconocibles para cualquicr profesional de la salud pública.

El libro cuenta con 16 capítulos. El primero está dedicado a exponer las principales perspectivas de análisis de los conflictos éticos: el principalismo (autonomía, beneficencia, no-maleficencia y justicia) y la casuística o razonamiento por analogía. Los siguientes capítulos tratan de áreas de conflicto en investigación epidemiológica y salud pública: confidencialidad, consentimiento informado, ensayos controlados, revisión de proyectos por comités adecuados, conducta inapropiada, conflicto de intereses, propiedad intelectual y cesión de datos, publicación e interpretación de resultados, práctica de la salud pública, estudios con poblaciones vulnerables, investigación en países culturalmente diferentes, investigación genética, prevención y tratamiento del sida y de la 
infección por VIH, y la asignación de recursos escasos. Cada capítulo contiene varios casos específicos organizados en: a) presentación del caso; b) varias preguntas para ampliar la discusión y; c) selección bibliográfica. Al final del libro se encuentra la guía del instructor, en la que se esbozan algunas líneas de razonamiento para tratar de resolver o para, al menos, simplificar el conflicto ético en unidades de análisis más abordables.

Es muy de agradecer el esfuerzo de recopilar casos prácticos con los que los lectores puedan fácilmente identificarse e implicarse, y el libro será de gran utilidad como material didáctico en cursos, seminarios, sesiones de departamento, etcétera. Su principal limitación es que la discusión de los casos es muchas veces minimalista, cuando no prácticamente inexistente. Esta puede ser una estrategia premeditada. Los autores de la obra son tres autoridades en la materia, responsables de varios libros recientes sobre el tema y con una experiencia profesional, docente y publica considerable (como miembros de SSCC de amplia proyección). Los autores pueden señalar así que los conflictos éticos no tienen todavía una respuesta única, sino que, aunque se sugiera en el libro el curso de actuación preferente, diferentes partes implicadas pueden tener puntos de vista distintos y se tendrá que seguir adelante, en situaciones de la vida real, a través del consenso y de la actuación «menos mala». Más aún, algunos dilemas todavía no tienen respuesta y tan sólo la casuística (recopilación y difusión sistemática de casos y sus resoluciones) puede ir creando el cuerpo de conocimientos y experiencias necesario para avanzar. De cualquier forma, el lector puede echar de menos una argumentación más elaborada.

El libro puede servir tanto de lectura para los profesionales con interés en este tipo de dilemas como material de referencia docente. Muy especialmente recomendable para jóvenes investigadores, que encontraran aquí un nombre para aquellas situaciones difíciles de catalogar (problemas en las autorías y asignación de mérito, cesión de ficheros a terceros, comunicación de riesgos, etc.). Otros libros relacionados sobre el tema (exclusivamente en inglés hasta el momento) son: Coughlin SS. Ethics in epidemiology and clinical research. Annotated Readings. Newton. Massachusetts: Epidemiology Resources Inc; 1995. Coughlin SS and Beauchamp TL, editors. Ethics and Epidemiology. New York \& Oxford: Oxford University Press; 1996. Y Coughlin SS. Ethics in Epidemiology and Public Health Practice: Collected Works. New York: Quill Publications/Steven S Coughlin; 1997.

El libro será bien recibido no sólo entre los profesionales de la epidemiología y la salud pública en sentido estricto, sino también entre aquellos profesionales de atención primaria que dedican parte de su labor investigadora a estudios llevados a cabo en sus poblaciones de referencia, el creciente número de investigadores en el área de la epidemiología clínica, los comités éticos de investigación clínica, así como los responsables de departamentos de investigación de las empresas farmacéuticas.

El libro esta escrito en ingles, pero su interés para los profesionales de lengua castellana (España y Latino América) justificaría su traducción al castellano. 